\title{
Synthesis of hyaluronic acid related di- and tetra-saccharides having a glucuronic acid at the reducing end
}

\author{
Ted M. Slagheka,", Teija K. Hyppönena, Tomoya Ogawab, Johannis P. Kamerlinga, and \\ Johannes F. G. Vliegentharta,
}

\author{
a Bijvet Center, Department of Bio-Organic Chemistry, Utrecht University, P.O. B0x 80.075, NL-3508 TB Utrecht, Netherlands \\ b The Institule of Physical and Chemical Research (RIKEN), Wako-shi, Saitama, 351-01 Japan \\ \# Present Address: Agricultural Research Institute (ATO-DLO), P.O. Box 17, NL-6700 AA Wageningen, Netherlands
}

\begin{abstract}
The synthesis is reponed of 4-methoxyphenyl $O$-(2-acetamido-2-deoxy- $\beta$-D-glucopyranosyl)-(1 $\rightarrow 4)-\beta$ D-glucopyranosyluronic acid (1) and 4-methoxyphenyl $O$-(2-acetanido-2-deoxy- $\beta$-D-glucopyranosyl)-(1-4)-0-( $\beta$ D-glucopyranosyluronic acid)-(1 $\rightarrow 3$ )- 0 -(2-acetamido-2-deoxy- $\beta$-D-glucopyranosyl)-(1 $\rightarrow 4)-\beta$-D-glucopyranosyluronic acid (5), which represent structural elements of hyaluronic acid. 3,4,6-Tri-O-acetyl-2-deoxy-2-phthalimido- $\beta$-Dglucopyranosyl trichloroacetimidate (3) was condensed with 4-methoxyphenyl 6-O-levulinoyl-2,3-di-O-p-toluoyl$\beta$-D-glucopyranoside (4) in dichloromethane, using boron trifluoride etherate as a promoter, yielding 4-methoxyphenyl $O$-(3,4,6-tri- $O$-acetyl-2-deoxy-2-phthalimido- $\beta$-D-glucopyranosyl)-(1 $\rightarrow 4)-6$ - $O$-levulinoyl-2,3-di- $O$ - $p$-toluoyl- $\beta$-D-glucopyranoside (2). Subsequent delevilinoylation, oxidation, complete deprotection, and $N$-acetylation gave 1. Coupling of 3-O-allyloxycarbonyl-2-deoxy-4,6-O-isopropylidene-2-phthalimido- $\beta$-D-glucopyranosyl trichloroacetimidate (9) with 4 , followed by de-allyloxycarbonylation of the obtained disaccharide derivative gave 4methoxyphenyl $O$-(2-deoxy-4,6-O-isopropylidene-2-phthalimido- $\beta$-D-glucopyranosyl)-(1 $\rightarrow 4)-6-O$-levulinoyl-2,3-di$O$-p-toluoyl- $\beta$-D-glucopyranoside (8). Demethoxyphenylation and subsequent imidation of 2 afforded $0-(3,4,6$-tri0 -acetyl-2-deoxy-2-phthalimido- $\beta$-D-glucopyranosyl $-(1 \rightarrow 4)-6$-0-levulinoyl-2,3-di- 0 -p-toluoyl- $\alpha / \beta$-D-glucopyranosyl trichloroacetimidate (7). Condensation of 7 with 8 in dichloromethane, with trimethylsilyl trifluoromethanesulfonate as a promoter, gave tetrasaccharide derivative 15. Subsequent de-isopropylidenation, $O$-acetylation, delevulinoylation, oxidation, complete deprotection, and $\mathrm{N}$-acelylation yielded $\mathbf{5}$.
\end{abstract}

\section{INTRODUCTION}

Hyaluronic acid (HA), a unique carbohydrate polymer belonging to the class of glycosaminoglycans, is the major component of several soft connective tissues and has also been found in certain bacterial strains. ${ }^{1}$ It is a linear, negatively charged polysaccharide ${ }^{2}$ consisting of a repeating disaccharide unit, namely, $[\rightarrow 4)-\beta-D$ GlcpA-(1 $\rightarrow 3)-\beta-D-G l c p N A c-(1 \rightarrow]_{n}$. The biopolymer is biosynthesised at the innerside of plasma membranes, ${ }^{3}$ and it plays an important role in structural functions, ${ }^{4}$ cell-cell recognition, 5 cell migration, ${ }^{6}$ and angiogenesis. ${ }^{7}$ As a medical aid, HA is used in opthalmic surgery 8 and woundhealing, ${ }^{9}$ and to combat joint diseases. ${ }^{10}$ Endo- 
thelial cell growth is inhibited by HA, but stimulated by enzymically generated fragments of HA (3-10 disaccharide units). 1,7 Isolation of the various oligosaccharides is laborious and sofar mainly mixtures of even numbered oligosaccharides were used in biological testing. ${ }^{7,11}$ The stimulating effect of HA oligosaccharides on angiogenesis initiated a research program on the synthesis of a wider range of medium-sized oligosaccharide elements constituted of even or odd numbers of monosaccharides with 2-acetamido-2-deoxy-D-glucose or D-glucuronic acid at the reducing end. Using these synthetic oligosaccharides it is aimed to study the biological activity of HA oligosaccharides in more detail. In earlier studies we have reported on the organic synthesis of the 4-methoxyphenyl (MP) glycosides of $\beta$-D-GlcpA-( $1 \rightarrow 3)$ - $\beta$-D-GlcpNAc, $\beta-D-G l c p N A c-(1 \rightarrow 4)-\beta-D-G l c p A-(1 \rightarrow 3)-\beta-D-$ GlcpNAc, and $\beta$-D-GlcpA- $(1 \rightarrow 3)-\beta$-D-GlcpNAc- $(1 \rightarrow 4)-\beta$-D-GlcpA- $(1 \rightarrow 3)-\beta-D-G l c p N A c .{ }^{12}$ This report describes the stereoselective synthesis of a di- and a tetra-saccharide fragment having the MP glycoside of $\beta$-D-glucuronic acid at the reducing end, namely, $\beta$-D-GlcpNAc- $(1 \rightarrow 4)-\beta-D-G l c p A-O M P$ and $\beta-D-G l c p N A c-(1 \rightarrow 4)-\beta$ D-GlcpA-(1 $\rightarrow 3)-\beta$-D-GlcpNAc- $(1 \rightarrow 4)-\beta$-D-GlcpA-OMP. A short communication with respect to the synthesis of the tetrasaccharide has appeared, ${ }^{13}$ and recently the synthesis of the methyl glycoside analogue of the disaccharide has been published by others. ${ }^{14}$

\section{RESULTS AND DISCUSSION}

For the synthesis of the two oligosaccharides 1 and 5 a series of monosaccharide coupling synthons were designed, namely $3,154,12$ and 9,12 which in principle also allow the extension to higher oligosaccharides (Schemes 1 and 2). 3,4,6-Tri- $O$-acetyl-2-deoxy-2-phthalimido- $\beta$-D-glucopyranosyl trichloroacetimidate (3) and 3-O-allyloxycarbonyl-2-deoxy-4,6-di- $O$-isopropylidene-2-phthalimido- $\beta$-D-glucopyranosyl trichloroacetimidate (9) are the precursors for the 2-acetamido-2-deoxy-D-glucose element in non-reducing terminal and internal position, respectively, whereas 4-methoxyphenyl 6- $O$-levulinoyl-2,3-di- $O$-p-toluoyl- $\beta$-D-glucopyranoside (4) is the precursor for the D-glucuronic acid element in glycosidic and internal position.

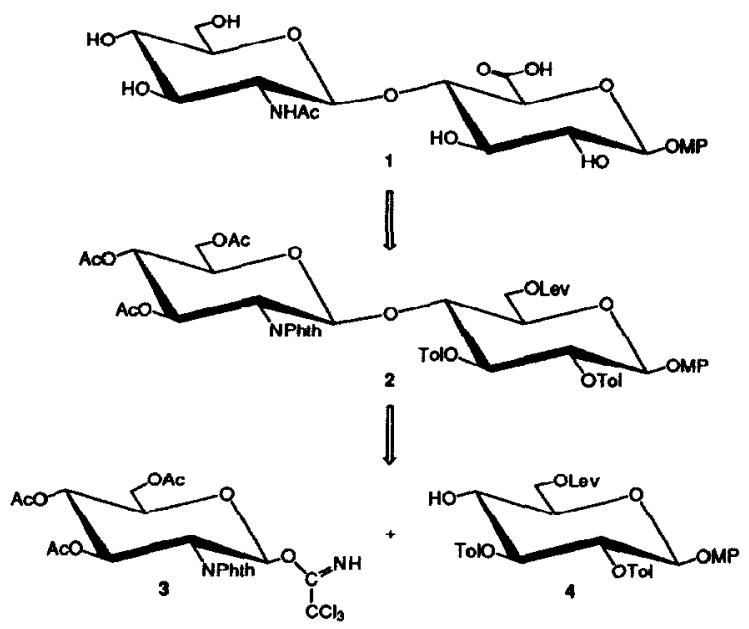

Scheme 1. Retrosynthetic analysis of disaccharide structure 1. Lev = levulinoyl; MP = 4-methoxyphenyl; Tol = $p$-toluoyl; Phth = phthaloyl; Ac = acetyl. 
Condensation of 3 with 4 (Scheme 1) in dichloromethane at room temperature, using boron trifluoride etherate as a promoter, gave disaccharide $2(81 \%)$, which was delevulinoylated using hydrazine acetate 16.17 in 1:2 toluene-ethanol to afford $10(86 \%)$. The oxidation of the primary hydroxyl group of the glucose unit in 10 was conducted in two steps, namely first a Swern oxidation with oxalyl chloride and methylsulfoxide ${ }^{18}$ followed by oxidation with $\mathrm{NaClO}_{2}, 19$ and it gave 11 in $68 \%$ yield (Scheme 3). Then, 11 was treated with methylamine ${ }^{20}$ in ethanol (de-acylation), followed by selective $\mathrm{N}$-acetylation using acetic anhydride in methanol to give $1(93 \%)$.

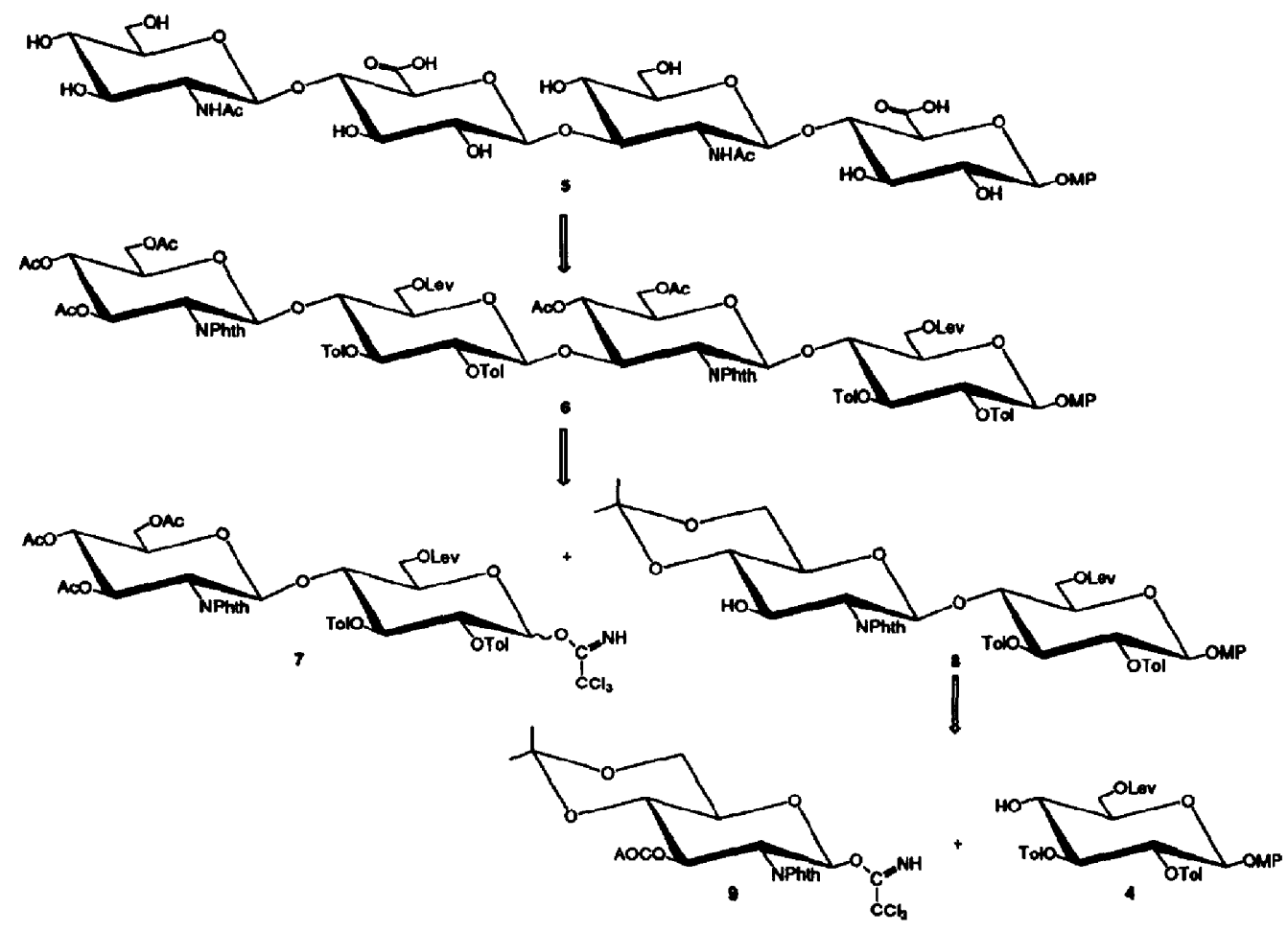

Scheme 2. Retrosynthetic analysis of tetrasaccharide structure $5 . A O C=$ allyloxycarbonyl.

Following the retrosynthetic analysis as presented in Scheme 2 for the synthesis of 5 , glycosyl donor 7 and glycosyl acceptor 8 were prepared. Demethoxyphenylation ${ }^{21}$ of 2 with ammonium cerium(IV) nitrate $(\rightarrow$ $12,96 \%$ ) followed by imidation with trichloroacetonitrile ${ }^{15}$ in the presence of 1,8-diazabicyclo[5.4.0]undec-7ene gave $7(93 \%)$. Condensation of 9 with 4 in dichloromethane at room temperature, using boron trifluoride etherate as a promoter, gave disaccharide derivative $13(90 \%)$. De-allyloxycarbonylation of 13 with tetrakis(triphenylphosphine) palladium in tetrahydrofuran and morpholine 22,23 yielded disaccharide derivative 8 (94\%).

Condensation of 7 with 8 in dichloromethane at $0^{\circ} \mathrm{C}$, using trimethylsilyl trifluoromethanesulfonate as a promoter afforded tetrasaccharide derivative 14. However, 14 could not be purified on silica; therefore the mixture containing 14 was treated with aqueous trifluoroacetic acid in dichloromethane (de-isopropylidenation) to 


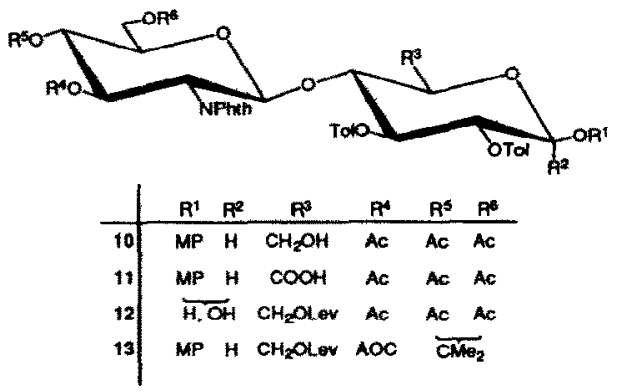

Scheme 3.

give 15 in $77 \%$ overall yield. After conventional $O$-acetylation $(\rightarrow 6,99 \%)$ and delevulinoylation using hydrazine acetate in $1: 2$ toluene-ethanol $(\rightarrow 16,87 \%)$, a Swern oxidation with oxalyl chloride and methylsulfoxide followed by oxidation with $\mathrm{NaClO}_{2}$ afforded 17 (76\%) (Scheme 4). Finally, 17 was de-acylated with methylamine in ethanol followed by selective $N$-acetylation using acetic anhydride in methanol. Because the $1 \mathbf{H}$ NMR spectrum showed the presence of one remaining $O$-acetyl group, an additional treatment with sodium methoxide in methanol was carried out to yield $5(61 \%)$.

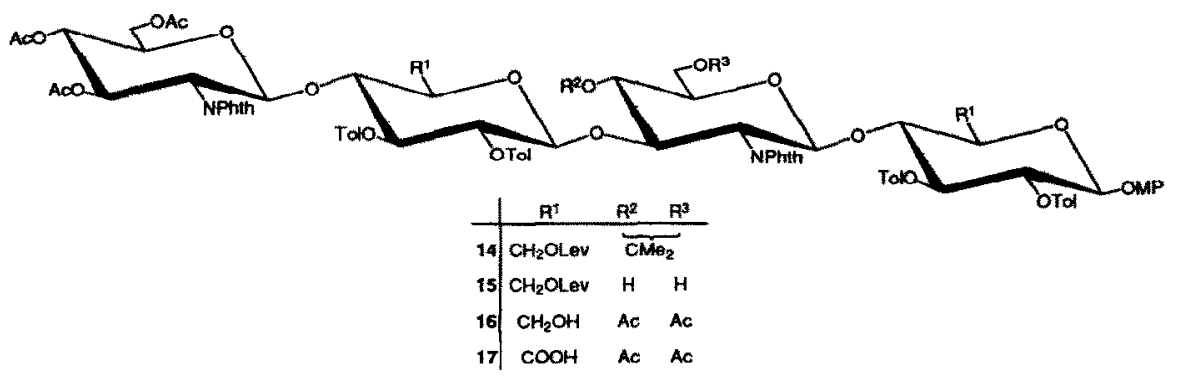

Scheme 4.

The synthesised MP glycosides $I$ and 5 will be tested in biological systems.

\section{EXPERIMENTAL}

General methods.-The ${ }^{1} \mathrm{H}\left(300\right.$ and $500 \mathrm{MHz}$ ) and ${ }^{13} \mathrm{C}$ (APT [attached proton test], 50 and $75 \mathrm{MHz}$ ) NMR spectra were recorded at $25^{\circ} \mathrm{C}$ with Bruker AC 300 , AM 500, or WP-200 spectrometers in $\mathrm{CDCl}_{3}$ unless stated otherwise. Chemical shifts ( $\delta$ ) are given in ppm relative to the signal for internal $\mathrm{Me}_{4} \mathrm{Si}\left(\mathrm{CDCl}_{3}\right)$ or internal sodium 4,4-dimethyl-4-silapentane-1-sulfonate $\left(\mathrm{D}_{2} \mathrm{O}\right.$; indirectly to internal acetone, $\left.\delta 2.225\right)$ for ${ }^{1} \mathrm{H}$, and to the signal for internal $\mathrm{Me}_{4} \mathrm{Si}\left(\mathrm{CDCl}_{3}\right.$; indirectly to $\left.\mathrm{CDCl}_{3}, \delta 76.9\right)$ or external $\mathrm{Me}_{4} \mathrm{Si}\left(\mathrm{D}_{2} \mathrm{O}\right.$; indirectly to internal acetone, 831.55 ) for ${ }^{13} \mathrm{C}$.

Reactions were monitored by TLC on Kieselgel $60 \mathrm{~F}_{254}$ (Merck). Detection was effected by examination under UV light and by charring with aq $50 \%$ sulfuric acid. Column chromatography was performed on Kiesel- 
gel 60 (Merck, 70-230 mesh). Optical rotations were measured for solutions in $\mathrm{CH}_{2} \mathrm{Cl}_{2}$, unless stated otherwise, at $20^{\circ} \mathrm{C}$ with a Perkin-Elmer 241 polarimeter, using a $10-\mathrm{cm} 1-\mathrm{mL}$ cell. Solvents were evaporated under reduced pressure at $40^{\circ} \mathrm{C}$ (bath). All solvents were distilled from the appropriate drying agents.

4-Methoxyphenyl O-(3,4,6-tri-O-acetyl-2-deoxy-2-phthalimido- $\beta$-D-glucopyranasyl)-(1-4)-6-0-levulinoyl-2,3-di-O-p-tolwoyl- $\beta$-D-glucopyranoside (2). - To a solution of 3,4,6-tri- $O$-acetyl-2-deoxy-2-phthalimido$\beta$-D-glucopyranosyl trichloroacetimidate $(3 ; 320 \mathrm{mg}, 0.55 \mathrm{mmol}$ ) and 4-methoxyphenyl 6-O-levulinoyl-2,3-di$O$-p-toluoyl- $\beta$-D-glucopyranoside (4; $228 \mathrm{mg}, 0.37 \mathrm{mmol}$ ) in $\mathrm{CH}_{2} \mathrm{Cl}_{2}(3.6 \mathrm{~mL}$ ) containing $4 \mathrm{~A}$ molecular sieves $\left(0.37 \mathrm{~g}\right.$ ) was added a solution of $\mathrm{M} \mathrm{BF}_{3} \cdot \mathrm{Et}_{2} \mathrm{O}$ in $\mathrm{CH}_{2} \mathrm{Cl}_{2}(204 \mu \mathrm{L})$. After stirring the mixture for $1 \mathrm{~h}$ at room temperature, TLC (1:1 toluene-acetone) showed the disappearance of 4 and the formation of $2\left(R_{\mathrm{F}} 0.62\right)$. Then the mixture was neutralised with triethylamine, diluted with EtOAc $(100 \mathrm{~mL})$, and washed with aq $5 \% \mathrm{NaCl}$ (30 $\mathrm{mL}$ ), and the organic layer was dried $\left(\mathrm{MgSO}_{4}\right)$, filtered, and concentrated. Column chromatography (1:1 toluene-acetone) of the residue yielded 2 , isolated as a syrup ( $310 \mathrm{mg}, 81 \%),[\alpha]_{D}+57$ (c 1). ${ }^{1} \mathrm{H}-\mathrm{NMR}$ data: $\delta$ 1.793, 1.918, and 1.965 ( $3 \mathrm{~s}$, each $3 \mathrm{H}, 3 \mathrm{Ac}$ ), 2.185 (s. $\left.3 \mathrm{H}, \mathrm{COCH}_{2} \mathrm{CH}_{2} \mathrm{COCH}_{3}\right), 2.355$ and $2.389(2 \mathrm{~s}$, each $\left.3 \mathrm{H}, 2 \mathrm{COC}_{6} \mathrm{H}_{4} \mathrm{CH}_{3}\right), 2.36-2.50$ and 2.63-2.65 (2 m, each $\left.2 \mathrm{H}, \mathrm{COCH}_{2} \mathrm{CH}_{2} \mathrm{COCH}_{3}\right), 3.706(\mathrm{~s}, 3 \mathrm{H}$, $\mathrm{C}_{6} \mathrm{H}_{4} \mathrm{OCH}_{3}$ ), 4.248 (dd, $\left.1 \mathrm{H}, J_{2^{\prime}, 1^{\prime}} 8.4, J_{2}^{\prime}, 3^{\prime} 10.6 \mathrm{~Hz}, \mathrm{H}-2^{\prime}\right), 5.027$ (d, $1 \mathrm{H}, J_{1,2} 7.7 \mathrm{~Hz}, \mathrm{H}-1$ ), 5.460 (dd, 1 $\mathrm{H}, J_{2,3} 8.8 \mathrm{~Hz}, \mathrm{H}-2$ ), $5.514\left(\mathrm{~d}, 1 \mathrm{H}, \mathrm{H}-1^{\prime}\right), 6.704$ and 6.823 (2 d, each $2 \mathrm{H}, \mathrm{C}_{6} \mathrm{H}_{4} \mathrm{OCH}_{3}$ ), 7.154, 7.195, 7.801 , and 7.901 ( $4 \mathrm{~d}$, each $\left.2 \mathrm{H}, 2 \mathrm{COC}_{6} \mathrm{H}_{4} \mathrm{CH}_{3}\right)$.

Anal. Calc. for $\mathrm{C}_{54} \mathrm{H}_{55} \mathrm{NO}_{20}$ : C, 62.48; $\mathrm{H}, 5.34$. Found: $\mathrm{C}, 62.10 ; \mathrm{H}, 5.28$.

4-Methoxyphenyl O-(3,4,6-tri-O-acetyl-2-deoxy-2-phthalimido- $\beta$-D-glucopyranosyl)-(1-A)-2,3-di-O-p-

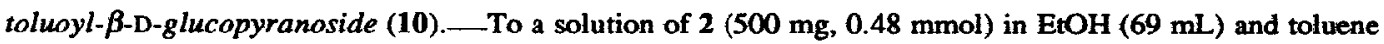
(34 mL) was added $\mathrm{NH}_{2} \mathrm{NH}_{2} \cdot \mathrm{HOAc}(222 \mathrm{mg}$ ). The mixture was stirred for $40 \mathrm{~min}$, when TLC (1:1 tolueneEtOAc) showed the conversion of 2 into $10\left(R_{\mathrm{F}} 0.55\right)$. Then the mixture was concentrated, and column chromatography (1:1 toluene-EtOAc) of the residue yielded 10 , isolated as a synup $(390 \mathrm{mg}, 86 \%),[\alpha]_{\mathrm{D}}+86$ (c 1$)$. NMR data: ${ }^{1} \mathrm{H}, \delta 1.799,1.909$, and 1.980 ( $3 \mathrm{~s}$, each $3 \mathrm{H}, 3 \mathrm{Ac}$ ), 2.349 and 2.393 ( $2 \mathrm{~s}$, each $3 \mathrm{H}, 2 \mathrm{COC}_{6} \mathrm{H}_{4}$ $\mathrm{CH}_{3}$ ), 3.704 (s, $3 \mathrm{H}, \mathrm{C}_{6} \mathrm{H}_{4} \mathrm{OCH}_{3}$ ), 4.243 (dd, $1 \mathrm{H}, J_{2}^{\prime}, 1^{\prime} 8.4, J_{2}^{\prime}, 3^{\prime} 10.7 \mathrm{~Hz}, \mathrm{H}-2^{\prime}$ ), 5.069 (d, $1 \mathrm{H}, J_{1,2} 7.8$ $\mathrm{Hz}, \mathrm{H}-1$ ), 5.437 (dd, $\left.1 \mathrm{H}, J_{2,3} 9.3 \mathrm{~Hz}, \mathrm{H}-2\right), 5.627$ (d, $1 \mathrm{H}, \mathrm{H}-1$ ), 6.701 and 6.805 (2 d, each $2 \mathrm{H}, \mathrm{C}_{6} \mathrm{H}_{4} \mathrm{O}-$ $\left.\mathrm{CH}_{3}\right), 7.145,7.213,7.795$, and 7.909 (4 d, each $\left.2 \mathrm{H}, 2 \mathrm{COC}_{6} \mathrm{H}_{4} \mathrm{CH}_{3}\right) ;{ }^{13} \mathrm{C}, \delta 20.2(2 \mathrm{C}$ ) and 20.3 (3 CO$\left.\mathrm{CH}_{3}\right), 21.3\left(\mathrm{COC}_{6} \mathrm{H}_{4} \mathrm{CH}_{3}\right), 54.7$ and $55.2\left(\mathrm{C}_{6} \mathrm{H}_{4} \mathrm{OCH}_{3}, \mathrm{C}-2^{\prime}\right), 60.2$ and $60.9\left(\mathrm{C}^{2} 6,6^{\prime}\right), 97.8\left(\mathrm{C}-1^{\prime}\right), 100.2$ $(\mathrm{C}-1), 114.2(2 \mathrm{C}), 118.3(2 \mathrm{C}), 150.7$, and $155.3\left(\mathrm{C}_{6} \mathrm{H}_{4} \mathrm{OCH}_{3}\right), 164.7$ and $164.9\left(2 \mathrm{COC}_{6} \mathrm{H}_{4} \mathrm{CH}_{3}\right), 169.0$, 169.8 , and $170.2\left(3 \mathrm{COCH}_{3}\right)$.

Anal. Calc. for $\mathrm{C}_{49} \mathrm{H}_{49} \mathrm{NO}_{18}$ : C, 62.61; $\mathrm{H}, 5.26$. Found: $\mathrm{C}, 62.04 ; \mathrm{H}, 5.38$.

4-Methoxyphenyl O-(3,4,6-tri-O-acetyl-2-deoxy-2-phthalimido- $\beta$-D-glucopyranosyl)-(I-4)-2,3-di-O-pzoluoyl- $\beta$-D-glucopyranosyluronic acid (11). - To a cold (-780 $\mathrm{C}$ ) $2 \mathrm{M}$ solution of oxalyl chloride in $\mathrm{CH}_{2} \mathrm{Cl}_{2}$ $(0.52 \mathrm{~mL})$ was added $\mathrm{Me}_{2} \mathrm{SO}(157 \mu \mathrm{L})$. After stirring for $10 \mathrm{~min}$, a solution of 10 (100 $\left.\mathrm{mg}, 0.11 \mathrm{mmol}\right)$ in $\mathrm{CH}_{2} \mathrm{Cl}_{2}(2.0 \mathrm{~mL})$ was added, and the mixture was stirred for $1 \mathrm{~h}$ at $-78^{\circ} \mathrm{C}$, whereby within $30 \mathrm{~min}$ a precipitate was observed. Diisopropylethylamine $(0.77 \mathrm{~mL})$ was added, and after $10 \mathrm{~min}$ the mixture was diluted with EtOAc $(35 \mathrm{~mL})$, washed with $\mathrm{M} \mathrm{HCl}(10 \mathrm{~mL})$ and aq saturated $\mathrm{NaCl}(10 \mathrm{~mL})$, and the organic layer was dried $\left(\mathrm{MgSO}_{4}\right)$, filtered, and concentrated. To a solution of the residue in $t-\mathrm{BuOH}(4.36 \mathrm{~mL}), 2$-methylbutene $(1.65$ 
$\mathrm{mL}$ ), and water $(2.7 \mathrm{~mL})$ were added $\mathrm{NaH}_{2} \mathrm{PO}_{4}(271 \mathrm{mg})$ and $\mathrm{NaClO}_{2}(271 \mathrm{mg})$. After stirring overnight, TLC (10:9:1 $\mathrm{CH}_{2} \mathrm{Cl}_{2}$-EtOAc-HOAc) showed the conversion of 10 into $11\left(R_{\mathrm{F}} 0.65\right)$. Then the mixture was concentrated, and a solution of the residue in water was washed with hexane, acidified with $\mathrm{M} \mathrm{HCl}$, and extracted with EtOAc $(3 \times 20 \mathrm{~mL})$. The organic layer was dried $\left(\mathrm{MgSO}_{4}\right)$, filtered, and concentrated. Column chromatography (3:2 $\mathrm{CH}_{2} \mathrm{Cl}_{2}$-EtOAc followed by $10: 9: 1 \mathrm{CH}_{2} \mathrm{Cl}_{2}-\mathrm{EtOAc}-\mathrm{HOAc}$ ) of the residue yielded 11, isolated as a syrup

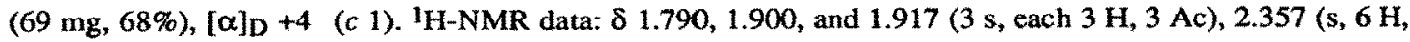
$2 \mathrm{COC}_{6} \mathrm{H}_{4} \mathrm{CH}_{3}$ ), 3.690 (s, $3 \mathrm{H}, \mathrm{C}_{6} \mathrm{H}_{4} \mathrm{OCH}_{3}$ ), 4.045 (d, $1 \mathrm{H}, J_{5,4} 9.2 \mathrm{~Hz}, \mathrm{H}-5$ ), 4.252 (dd, $1 \mathrm{H}, J_{2}, 1,8.4$, $J_{2}^{\prime}, 3^{\prime} 10.7 \mathrm{~Hz}, \mathrm{H}-2^{\prime}$ ), 5.122 (d, $1 \mathrm{H}, J_{1,2} 7.3 \mathrm{~Hz}, \mathrm{H}-1$ ), $5.546\left(\mathrm{~d}, 1 \mathrm{H}, \mathrm{H}-1\right.$ ), 5.595 (dd, $1 \mathrm{H}, J_{2,3}, 9.0 \mathrm{~Hz}, \mathrm{H}-$ 2), 6.691 and $6.840\left(2 \mathrm{~d}\right.$, each $2 \mathrm{H}, \mathrm{C}_{6} \mathrm{H}_{4} \mathrm{OCH}_{3}$ ), 7.159, 7.165, 7.815, and 7.898 (4 d, each $2 \mathrm{H}, 2 \mathrm{COC}_{6} \mathrm{H}_{4}$ $\mathrm{CH}_{3}$ ). A small amount of 11 was esterified with diazomethane in ether, and analysed by ${ }^{1} \mathrm{H} N \mathrm{NR}: \delta 1.800$, 1.920, and $1.950(3 \mathrm{~s}$, each $3 \mathrm{H}, 3 \mathrm{Ac}), 2.356$ and $2.381\left(2 \mathrm{~s}\right.$, each $\left.3 \mathrm{H}, 2 \mathrm{COC}_{6} \mathrm{H}_{4} \mathrm{CH}_{3}\right), 3.493(\mathrm{~s}, 3 \mathrm{H}, \mathrm{CO}$ $\left.\mathrm{OCH}_{3}\right), 3.707\left(\mathrm{~s}, 3 \mathrm{H}, \mathrm{C}_{6} \mathrm{H}_{4} \mathrm{OCH}_{3}\right), 4.031\left(\mathrm{~d}, 1 \mathrm{H}, J_{5,4} 9.2 \mathrm{~Hz}, \mathrm{H}-5\right.$ ), 4.205 (dd, $1 \mathrm{H}, J_{2}^{\prime}, 1^{\prime} 8.4, J_{2^{\prime}, 3^{\prime}} 10.7$ $\mathrm{Hz}, \mathrm{H}-2$ ), 5.095 (d, $1 \mathrm{H}, J_{1,2} 7.1 \mathrm{~Hz}, \mathrm{H}-1$ ), 5.464 (d, $1 \mathrm{H}, \mathrm{H}-1^{\prime}$ ), 5.492 (dd, $1 \mathrm{H}, J_{2,3} 8.9 \mathrm{~Hz}, \mathrm{H}-2$ ), 6.700 and $6.814\left(2 \mathrm{~d}\right.$, each $\left.2 \mathrm{H}, \mathrm{C}_{6} \mathrm{H}_{4} \mathrm{OCH}_{3}\right), 7.161,7.189,7.803$, and 7.900 (4 d, each $2 \mathrm{H}, 2 \mathrm{COC}_{6} \mathrm{H}_{4} \mathrm{CH}_{3}$ ).

4-Methoxyphenyl O-(2-acetamido-2-deoxy- $\beta$-D-glucopyranosyl)-(1-4)- $\beta$-D-glucopyranosyluronic acid (1). A solution of $11(69 \mathrm{mg}, 70 \mu \mathrm{mol})$ in ethanolic $30 \%$ methylamine $(20 \mathrm{~mL})$ was stirred for 3 days, when TLC (4:2:2:1 n-BuOH-EtOH- $\mathrm{H}_{2} \mathrm{O}-\mathrm{HOAc}$ ) showed the conversion of 11 into an intermediate amino compound $\left(R_{\mathrm{F}} 0.70\right)$. The mixture was concentrated, and a solution of the residue in $\mathrm{MeOH}(15.6 \mathrm{~mL})$ and acetic anhydride $(219 \mu \mathrm{L})$ was stirred for $2 \mathrm{~h}$ at $0{ }^{\circ} \mathrm{C}$, then concentrated, and $1: 1$ toluene-MeOH $(3 \times 15 \mathrm{~mL})$ was evaporated from the residue. Compound 1 was purified by FPLC on Q-Sepharose using a concentration gradient of 0 to $150 \mathrm{mM}$ NaCl. After desalting on Bio-Gel P-2 and lyophilisation, 1 was obtained as an amorphous, white pow-

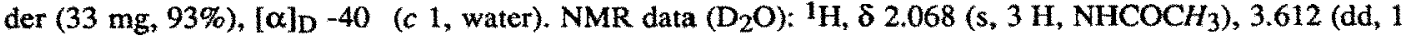
$\left.\mathrm{H}, J_{2,3} 9.5 \mathrm{~Hz}, \mathrm{H}-2\right), 3.728\left(\mathrm{dd}, 1 \mathrm{H}, J_{2^{\prime}, 3^{\prime}} 10.2 \mathrm{~Hz}, \mathrm{H}-2^{\prime}\right), 3.802\left(\mathrm{~s}, 3 \mathrm{H}, \mathrm{C}_{6} \mathrm{H}_{4} \mathrm{OCH}_{3}\right), 4.576\left(\mathrm{~d}, 1 \mathrm{H}, J_{1^{\prime}, 2^{\prime}}\right.$ $8.4 \mathrm{~Hz}, \mathrm{H}-1$ ), 4.991 (d, $\left.1 \mathrm{H}, J_{1,2} 7.8 \mathrm{~Hz}, \mathrm{H}-1\right), 6.964$ and $7.095\left(2 \mathrm{~d}\right.$, each $\left.2 \mathrm{H}, \mathrm{C}_{6} \mathrm{H}_{4} \mathrm{OCH}_{3}\right) ;{ }^{13} \mathrm{C}, \delta 23.7$ $\left(\mathrm{NHCOCH}_{3}\right), 56.7$ and $57.1\left(\mathrm{C}_{6} \mathrm{H}_{4} \mathrm{OCH}_{3}, \mathrm{C}-2^{2}\right), 61.9(\mathrm{C}-6), 102.1$ and $102.6\left(\mathrm{C}-1,1^{\prime}\right), 116.4(2 \mathrm{C}), 119.5$ (2 C), 152.2 , and $156.0\left(\mathrm{C}_{6} \mathrm{H}_{4} \mathrm{OCH}_{3}\right), 175.2$ and $176.2\left(\mathrm{NHCOCH}_{3}, \mathrm{COOH}\right) ; \mathrm{FAB}-\mathrm{MS} \mathrm{m} / z 504[\mathrm{M}+\mathrm{H}]^{+}$.

\section{O-(3,4,6-Tri-O-acetyl-2-deoxy-2-phthalimido- $\beta$-D-glucopyranosyl)-(l-4)-6-O-levulinoyl-2,3-di-O-p-} toluoyl- $\alpha$ / $\beta$-D-glucopyranose (12). - To a solution of $2(3.00 \mathrm{~g}, 2.89 \mathrm{mmol})$ in toluene $(121 \mathrm{~mL})$ and acetonitrile $(170 \mathrm{~mL})$ was added water $(121 \mathrm{~mL})$ and ammonium cerium(IV) nitrate $(16.0 \mathrm{~g})$. After stirring for 75 min, TLC (6:1 CH $\mathrm{CH}_{2}$-acetone) showed a complete conversion of 2 into $12\left(R_{\mathrm{F}} 0.30\right)$. Then, the mixture was diluted with EtOAc $(300 \mathrm{~mL})$, washed with aq saturated $\mathrm{NaHCO}_{3}(2 \times 100 \mathrm{~mL})$ and water $(2 \times 100 \mathrm{~mL})$. The organic layer was dried $\left(\mathrm{MgSO}_{4}\right)$, filtered, and concentrated. Column chromatography $\left(9: 1 \mathrm{CH}_{2} \mathrm{Cl}_{2}\right.$-acetone) of the residue yielded 12 , isolated as a syrup $(2.8 \mathrm{~g}, 96 \%),[\alpha] \mathrm{D}+93(c) 1)(\alpha: \beta 2.7: 1) .{ }^{13} \mathrm{C}-\mathrm{NMR}$ data: $\delta 20.4$, 20.5, and $20.7\left(3 \mathrm{COCH}_{3}\right), 21.6\left(\mathrm{COC}_{6} \mathrm{H}_{4} \mathrm{CH}_{3}\right), 27.7,29.9$, and $38.0\left(\mathrm{COCH}_{2} \mathrm{CH}_{2} \mathrm{COCH}_{3}\right), 54.9\left(\mathrm{C}-2^{\prime}\right)$, 61.3 and $62.1\left(\mathrm{C}-6,6^{\prime}\right), 90.1(\mathrm{C}-1 \alpha), 95.4(\mathrm{C}-1 \beta), 97.7\left(\mathrm{C}-1^{\prime}\right), 165.0$ and $166.0\left(2 \mathrm{COC}_{6} \mathrm{H}_{4} \mathrm{CH}_{3}\right), 169.3$, 170.2, and $170.6\left(3 \mathrm{COCH}_{3}\right), 172.0\left(\mathrm{COCH}_{2} \mathrm{CH}_{2} \mathrm{COCH}_{3}\right), 206.8\left(\mathrm{COCH}_{2} \mathrm{CH}_{2} \mathrm{COCH}_{3}\right)$.

Anal. Calc. for $\mathrm{C}_{47} \mathrm{H}_{49} \mathrm{NO}_{19}: \mathrm{C}, 60.57 ; \mathrm{H}, 5.30$. Found: $\mathrm{C}, 60.06 ; \mathrm{H}, 5.25$.

O-(3,4,6-Tri-O-aceryl-2-deoxy-2-phthalimido- $\beta$-D-glucopyranosyl $)-(1 \rightarrow 4)-6-0$-levulinoyl-2,3-di-O-p- 
toluoyl- $\alpha / \beta$-D-glucopyranosyl trichloroacetimidate (7).-To a solution of $12(2.6 \mathrm{~g}, 2.8 \mathrm{mmol})$ in $\mathrm{CH}_{2} \mathrm{Cl}_{2}$ $(8.0 \mathrm{~mL})$ and trichloroacetonitrile $(3.0 \mathrm{~mL})$ was added 1,8-diazabicyclo[5.4.0]undec-7-ene (101 $\mu \mathrm{L})$. After stirring overnight, $\mathrm{TLC}\left(9: 1 \mathrm{CH}_{2} \mathrm{Cl}_{2}\right.$-acetone) showed a complete conversion of 12 into $7\left(R_{\mathrm{F}} 0.47\right)$, and the mixture was purified by column chromatography $\left(9: 1 \mathrm{CH}_{2} \mathrm{Cl}_{2}\right.$-acetone) to yield 7 , isolated as a syrup $(2.8 \mathrm{~g}, 93 \%)$, $[\alpha]_{D}+80$ (c 1) ( $\left.\alpha: \beta 3: 2\right)$. NMR data: ${ }^{1} \mathrm{H}, \delta 1.789,1.912$, and $1.978(3 \mathrm{~s}$, each $3 \mathrm{H}, 3 \mathrm{Ac}$ ), $2.209(\mathrm{~s}, 3 \mathrm{H}$, $\mathrm{COCH}_{2} \mathrm{CH}_{2} \mathrm{COCH}_{3}$ ), 2.327 and 2.379 (2 s, cach $\left.3 \mathrm{H}, 2 \mathrm{COC}_{6} \mathrm{H}_{4} \mathrm{CH}_{3}\right), 2.27-2.52$ and 2.67-2.72 (2 m, each 2 $\mathrm{H}, \mathrm{COCH}_{2} \mathrm{CH}_{2} \mathrm{COCH}_{3}$ ), 5.585 (d, $\left.1 \mathrm{H}, J_{1}^{\prime}, 28.1 \mathrm{~Hz}, \mathrm{H}-1^{\prime}\right), 6.600$ (d, $0.6 \mathrm{H}, J_{1,2} 3.7 \mathrm{~Hz}, \mathrm{H}-1 \alpha$ ), 6.631 (d, $\left.0.4 \mathrm{H}, J_{1,2} 8.8 \mathrm{~Hz}, \mathrm{H}-1 \beta\right) ;{ }^{13} \mathrm{C}, \delta 20.3,20.5$, and $20.7\left(3 \mathrm{COCH}_{3}\right), 21.7\left(\mathrm{COC}_{6} \mathrm{H}_{4} \mathrm{CH}_{3}\right), 27.6,29.9$, and

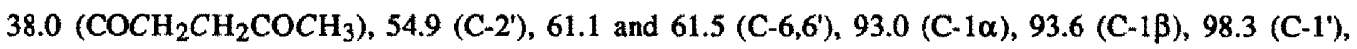
$160.7\left(\mathrm{NHCCl}_{3}\right), 164.8$ and $165.6\left(2 \mathrm{COC}_{6} \mathrm{H}_{4} \mathrm{CH}_{3}\right), 169.2,170.1$, and $170.5\left(3 \mathrm{COCH}_{3}\right), 171.8\left(\mathrm{COCH}_{2}-\right.$ $\left.\mathrm{CH}_{2} \mathrm{COCH}_{3}\right), 206.1\left(\mathrm{COCH}_{2} \mathrm{CH}_{2} \mathrm{COCH}_{3}\right)$.

Anal. Calc. for $\mathrm{C}_{49} \mathrm{H}_{49} \mathrm{Cl}_{3} \mathrm{~N}_{2} \mathrm{O}_{19}: \mathrm{C}, 54.68 ; \mathrm{H}, 4.59$. Found: $\mathrm{C}, 54.68 ; \mathrm{H}, 4.50$.

4-Methoxyphenyl O-(3-0-allyloxycarbonyl-2-deoxy-4,6-O-isopropylidene-2-phthalimido- $\beta$-D-glucopyranosyl)-( $(1 \rightarrow 4)-6-\mathrm{O}$-levulinoyl-2,3-di-O-p-toluoyl- $\beta$-D-glucopyranoside (13). - To a solution of 3-O-allyloxycarbonyl-2-deoxy-4,6- $O$-isopropylidene-2-phthalimido- $\beta$-D-glucopyranosyl trichloroacetimidate $(9 ; 200 \mathrm{mg}$, $0.35 \mathrm{mmol})$ and $4(143 \mathrm{mg}, 0.23 \mathrm{mmol})$ in $\mathrm{CH}_{2} \mathrm{Cl}_{2}(1.8 \mathrm{~mL})$ containing $4 \mathrm{~A}$ molecular sieves $(0.14 \mathrm{~g})$ was added a solution of $\mathrm{M} \mathrm{BF}_{3} \cdot \mathrm{Et}_{2} \mathrm{O}$ in $\mathrm{CH}_{2} \mathrm{Cl}_{2}(851 \mu \mathrm{L})$. After stirring the mixture for $45 \mathrm{~min}$ at room temperature, TLC (95:5 $\mathrm{CH}_{2} \mathrm{Cl}_{2}$-acetone) showed the disappearance of 4 and the formation of $13\left(R_{\mathrm{F}} 0.43\right)$. Then, triethylamine was added to neutralize and the mixture was diluted with EtOAc $(100 \mathrm{~mL})$, washed with aq $5 \% \mathrm{NaCl}$, and the organic layer was dried $\left(\mathrm{MgSO}_{4}\right)$, filtered, and concentrated. Column chromatography $\left(95: 5 \mathrm{CH}_{2} \mathrm{Cl}_{2-}\right.$ acetone) of the residue yielded 13 , isolated as a syrup $(215 \mathrm{mg}, 90 \%),[\alpha]_{\mathrm{D}}+25(c 1)$. NMR data: ${ }^{1} \mathrm{H}, \delta$ 1.224 and $1.254\left[2 \mathrm{~s}\right.$, each $\left.3 \mathrm{H}, \mathrm{C}\left(\mathrm{CH}_{3}\right)_{2}\right], 2.188\left(\mathrm{~s}, 3 \mathrm{H}, \mathrm{COCH}_{2} \mathrm{CH}_{2} \mathrm{COCH}_{3}\right), 2.338$ and $2.390(2 \mathrm{~s}$, each 3 $\left.\mathrm{H}, 2 \mathrm{COC}_{6} \mathrm{H}_{4} \mathrm{CH}_{3}\right), 2.37-2.50$ and 2.63-2.80 (2 m, each $\left.2 \mathrm{H}, \mathrm{COCH}_{2} \mathrm{CH}_{2} \mathrm{COCH}_{3}\right), 3.695\left(\mathrm{~s}, 3 \mathrm{H}, \mathrm{C}_{6} \mathrm{H}_{4} \mathrm{O}-\right.$ $\left.\mathrm{CH}_{3}\right), 4.220$ (dd, $\left.1 \mathrm{H}, J_{2}, 3^{\prime} 10.2 \mathrm{~Hz}, \mathrm{H}-2^{\prime}\right), 4.963$ and $5.059\left(2 \mathrm{~m}\right.$, each $1 \mathrm{H}, \mathrm{COOCH}_{2} \mathrm{CH}_{m} \mathrm{CH}_{2}$ ), 5.026 (d, $\left.1 \mathrm{H}, J_{1,2} 7.5 \mathrm{~Hz}, \mathrm{H}-1\right), 5.408\left(\mathrm{~d}, 1 \mathrm{H}, J_{1}, 2,8.0 \mathrm{~Hz}, \mathrm{H}-1^{\prime}\right), 5.490$ (dd, $1 \mathrm{H}, J_{2,3} 9.2 \mathrm{~Hz}, \mathrm{H}-2$ ), 6.696 and $6.824\left(2 \mathrm{~d}\right.$, each $\left.2 \mathrm{H}, \mathrm{C}_{6} \mathrm{H}_{4} \mathrm{OCH}_{3}\right), 7.138,7.237,7.810$, and $7.921\left(4 \mathrm{~d}\right.$, each $\left.2 \mathrm{H}, 2 \mathrm{COC}_{6} \mathrm{H}_{4} \mathrm{CH}_{3}\right) ;{ }^{13} \mathrm{C}, \delta$ $18.4\left[\mathrm{C}\left(\mathrm{CH}_{3}\right)_{2}\right], 21.4\left(2 \mathrm{COC}_{6} \mathrm{H}_{4} \mathrm{CH}_{3}\right), 27.4,29.6$, and $37.7\left(\mathrm{COCH}_{2} \mathrm{CH}_{2} \mathrm{COCH}_{3}\right), 55.3\left(\mathrm{C}-2{ }^{\prime}, \mathrm{C}_{6} \mathrm{H}_{4} \mathrm{O}-\right.$ $\left.\mathrm{CH}_{3}\right), 60.8$ and $61.7\left(\mathrm{C}-6,6^{\prime}\right), 68.2\left(\mathrm{COOCH}_{2} \mathrm{CH}=\mathrm{CH}_{2}\right), 98.4\left(\mathrm{C}-1^{\circ}\right), 99.3\left[\mathrm{C}\left(\mathrm{CH}_{3}\right)_{2}\right], 100.2(\mathrm{C}-1), 114.2$ (2 C), $118.7(2 \mathrm{C}), 150.8$, and $155.4\left(\mathrm{C}_{6} \mathrm{H}_{4} \mathrm{OCH}_{3}\right), 118.3\left(\mathrm{COOCH}_{2} \mathrm{CH}=\mathrm{CH}_{2}\right), 130.8\left(\mathrm{COOCH}_{2} \mathrm{CH}=\mathrm{CH}_{2}\right)$, $164.9\left(\mathrm{COC}_{6} \mathrm{H}_{4} \mathrm{CH}_{3}\right), 171.6\left(\mathrm{COCH}_{2} \mathrm{CH}_{2} \mathrm{COCH}_{3}\right)$.

Anal. Calc. for $\mathrm{C}_{55} \mathrm{H}_{57} \mathrm{NO}_{19}$ : C, 63.75; $\mathrm{H}, 5.55$. Found: $\mathrm{C}, 63.52 ; \mathrm{H}, 5.64$.

4-Methoxyphenyl O-(2-deoxy-4,6-O-isopropylidene-2-phthalimido- $\beta$-D-glucopyranosyl)-(1-4)-6-Olevulinoyl-2,3-di-O-p-toluoyl- $\beta$-D-glucopyranoside (8)._. To a solution of 13 (433 mg, $0.42 \mathrm{mmol}$ ) in tetrahydrofuran $(7.0 \mathrm{~mL})$ and morpholine $(300 \mu \mathrm{L})$ was added tetrakis(triphenylphosphine) palladium $(83.6 \mathrm{mg})$. The mixture was boiled under reflux for $30 \mathrm{~min}$, when TLC $\left(9: 1 \mathrm{CH}_{2} \mathrm{Cl}_{2}\right.$-acetone) showed the de- $O$-allyloxycarbonylation to be complete $\left(8 ; R_{\mathrm{F}} 0.29\right)$. Then the mixture was diluted with EtOAc $(50 \mathrm{~mL})$, washed with aq $5 \% \mathrm{NaCl}(3 \times 20 \mathrm{~mL})$, and the organic layer was dried $\left(\mathrm{MgSO}_{4}\right)$, filtered, and concentrated. Column chromatography (9:1 $\mathrm{CH}_{2} \mathrm{Cl}_{2}$-acetone) of the residue yielded 8 , isolated as a syrup $(359 \mathrm{mg}, 94 \%),[\alpha]_{\mathrm{D}}+31$ (c 1$)$. NMR data: ${ }^{1} \mathrm{H}, \delta 1.239$ and $1.250\left[2 \mathrm{~s}\right.$, each $\left.3 \mathrm{H}, \mathrm{C}\left(\mathrm{CH}_{3}\right) 2\right], 2.160\left(\mathrm{~s}, 3 \mathrm{H}, \mathrm{COCH}_{2} \mathrm{CH}_{2} \mathrm{COCH}_{3}\right), 2.316$ and 
$2.370\left(2 \mathrm{~s}\right.$, each $\left.3 \mathrm{H}, 2 \mathrm{COC}_{6} \mathrm{H}_{4} \mathrm{CH}_{3}\right), 3.678\left(\mathrm{~s}, 3 \mathrm{H}_{\mathrm{x}} \mathrm{C}_{6} \mathrm{H}_{4} \mathrm{OCH}\right.$ ), $5.048\left(\mathrm{~d}, 1 \mathrm{H}, J_{1,2} 7.5 \mathrm{~Hz}, \mathrm{H}-1\right), 5.287$ (d, $\left.1 \mathrm{H}, J_{1}, 2 \cdot 8.2 \mathrm{~Hz}, \mathrm{H}-1\right), 5.489$ (dd, $\left.1 \mathrm{H}, J_{2,3} 9.1 \mathrm{~Hz}, \mathrm{H}-2\right), 6.688$ and 6.822 (2 d, each $2 \mathrm{H}, \mathrm{C}_{6} \mathrm{H}_{4} \mathrm{O}-$ $\left.\mathrm{CH}_{3}\right), 7.132,7.213,7.802$, and $7.901\left(4 \mathrm{~d}\right.$, each $\left.2 \mathrm{H}, 2 \mathrm{COC}_{6} \mathrm{H}_{4} \mathrm{CH}_{3}\right) ;{ }^{13} \mathrm{C}, \delta 18.6\left[\mathrm{C}\left(\mathrm{CH}_{3}\right)_{2}\right], 21.3(\mathrm{CO}-$ $\left.\mathrm{C}_{6} \mathrm{H}_{4} \mathrm{CH}_{3}\right), 27.4,29.5$, and $37.7\left(\mathrm{COCH}_{2} \mathrm{CH}_{2} \mathrm{COCH}_{3}\right), 55.3$ and $56.9\left(\mathrm{C}-2, \mathrm{C}_{6} \mathrm{H}_{4} \mathrm{OCH}_{3}\right), 60.9$ and 61.8 $\left(\mathrm{C}-6,6^{\prime}\right), 98.7\left(\mathrm{C}-1^{\prime}\right), 98.2\left[C\left(\mathrm{CH}_{3}\right)_{2}\right], 100.0(\mathrm{C}-1), 114.3(2 \mathrm{C}), 118.6(2 \mathrm{C}), 150.8$, and $155.5\left(C_{6} \mathrm{H}_{4} \mathrm{O}-\right.$ $\left.\mathrm{CH}_{3}\right), 164.8\left(\mathrm{COC}_{6} \mathrm{H}_{4} \mathrm{CH}_{3}\right), 171.5\left(\mathrm{COCH}_{2} \mathrm{CH}_{2} \mathrm{COCH}_{3}\right)$.

Anal. Calc. for $\mathrm{C}_{51} \mathrm{H}_{53} \mathrm{NO}_{17}: \mathrm{C}, 64.34 ; \mathrm{H}, 5.61$. Found: $\mathrm{C}, 64.33 ; \mathrm{H}, 5.66$.

4-Methoxyphenyl O-(3,4,6-tri-O-acetyl-2-deoxy-2-phthalimido- $\beta$-D-glucopyranosyl $)-(1 \rightarrow 4)-\mathrm{O}-(6-\mathrm{O}-$ le-

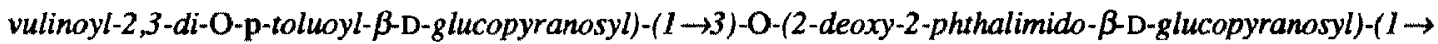
4)-6-O-levulinoyl-2,3-di-O-p-tolwoyl- $\beta$-D-glucopyranoside (15). - To a solution of 7 (761 $\mathrm{mg}, 0.71 \mathrm{mmol}$ ) and 8 ( $269 \mathrm{mg}, 0.28 \mathrm{mmol}$ ) in $\mathrm{CH}_{2} \mathrm{Cl}_{2}(2.8 \mathrm{~mL}$ ) containing $4 \mathrm{~A}$ molecular sieves ( $283 \mathrm{mg}$ ) was added a solution of $\mathrm{M} \mathrm{CF}_{3} \mathrm{SO}_{3} \mathrm{SiMe}_{3}$ in $\mathrm{CH}_{2} \mathrm{Cl}_{2}(66 \mu \mathrm{L})$ at $0{ }^{\circ} \mathrm{C}$. After stirring the mixture for 60 min at room temperature, TLC (9:1 $\mathrm{CH}_{2} \mathrm{Cl}_{2}$-acetone) showed the disappearance of 8 and the formation of $14\left(R_{\mathrm{F}} 0.50\right)$. Then, triethylamine was added to neutralize, and the mixture was diluted with EtOAc $(100 \mathrm{~mL})$, washed with aq $5 \% \mathrm{NaCl}(3 \times 30$ $\mathrm{mL}$ ), and the organic layer was dried $\left(\mathrm{MgSO}_{4}\right)$, filtered, and concentrated. The residue was dissolved in $\mathrm{CH}_{2} \mathrm{Cl}_{2}(5.3 \mathrm{~mL})$, and trifluoroacetic acid $(300 \mu \mathrm{L})$ and water $(37 \mu \mathrm{L})$ were added. After stirring the mixture for $60 \mathrm{~min}$, TLC (85:15 $\mathrm{CH}_{2} \mathrm{Cl}_{2}$-acetone) showed the de-isopropylidenation to be complete $\left(15 ; R_{\mathrm{F}} 0.44\right)$. Then, the mixture was washed with aq saturated $\mathrm{NaHCO}_{3}(3 \times 25 \mathrm{~mL})$ and water $(3 \times 25 \mathrm{~mL})$, and the organic layer was dried $\left(\mathrm{MgSO}_{4}\right)$, filtered, and concentrated. Column chromatography $\left(9: 1 \mathrm{CH}_{2} \mathrm{Cl}_{2}\right.$-acetone) of the residue yielded 15 , isolated as a syrup $(400 \mathrm{mg}, 77 \%),[\alpha]_{\mathrm{D}}+70$ (c 1). NMR data: ${ }^{1} \mathrm{H}, \delta 1.768,1.889$, and $1.923(3$ s, each $3 \mathrm{H}, 3 \mathrm{Ac}$ ), 2.162 and $2.166\left(2 \mathrm{~s}\right.$, each $\left.3 \mathrm{H}, 2 \mathrm{COCH}_{2} \mathrm{CH}_{2} \mathrm{COCH}_{3}\right), 2.305,2.341$, and 2.380 (3 s, $\left.3,6,3 \mathrm{H}, 4 \mathrm{COC}_{6} \mathrm{H}_{4} \mathrm{CH}_{3}\right), 3.683\left(\mathrm{~s}, 3 \mathrm{H}, \mathrm{C}_{6} \mathrm{H}_{4} \mathrm{OCH}_{3}\right), 4.155$ and $4.336\left(2 \mathrm{dd}\right.$, each $1 \mathrm{H}, J_{2}^{\prime}, 1^{\prime} / 2^{m}, 1^{m} 8.2$ and

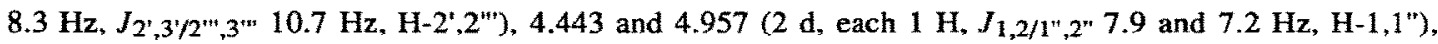

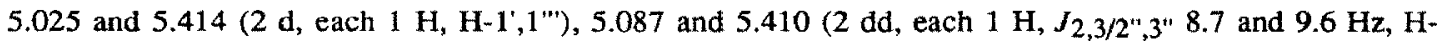
$\left.2,2^{\prime \prime}\right), 6.667$ and $6.779\left(2 \mathrm{~d}\right.$, each $\left.2 \mathrm{H}, \mathrm{C}_{6} \mathrm{H}_{4} \mathrm{OCH}_{3}\right), 6.865,7.055,7.136,7.181,7.279,7.653,7.773$, and $7.836\left(8 \mathrm{~d}\right.$, each $\left.2 \mathrm{H}, 4 \mathrm{COC}_{6} \mathrm{H}_{4} \mathrm{CH}_{3}\right) ;{ }^{13} \mathrm{C}, \delta 20.2,20.4$, and $20.5\left(3 \mathrm{COCH}_{3}\right), 21.5\left(\mathrm{COC}_{6} \mathrm{H}_{4} \mathrm{CH}_{3}\right), 27.4$, $27.6,29.2,29.7$, and 37.7 ( $2 \mathrm{C})\left(\mathrm{COCH}_{2} \mathrm{CH}_{2} \mathrm{COCH}_{3}\right), 54.8$ and $55.5(2 \mathrm{C})\left(\mathrm{C}-2^{\prime}, 2^{\prime \prime}, \mathrm{C}_{6} \mathrm{H}_{4} \mathrm{OCH}_{3}\right), 61.2$ and $62.0\left(\mathrm{C}-6,6^{\circ}, 6^{\prime \prime}, 6^{\prime \prime}\right), 97.5\left(\mathrm{C}-1^{\prime}, 1^{\prime \prime}\right), 99.9$ and $100.8\left(\mathrm{C}-1,1^{\prime \prime}\right), 114.4(2 \mathrm{C}), 118.7(2 \mathrm{C}), 150.9$, and $155.5\left(\mathrm{C}_{6} \mathrm{H}_{4} \mathrm{OCH}_{3}\right), 164.7$ and $165.1\left(\mathrm{COC}_{6} \mathrm{H}_{4} \mathrm{CH}_{3}\right), 169.1,169.8$, and $170.3\left(3 \mathrm{COCH}_{3}\right), 171.6$ $\left(\mathrm{COCH}_{2} \mathrm{CH}_{2} \mathrm{COCH}_{3}\right)$.

Anal. Calc. for $\mathrm{C}_{95} \mathrm{H}_{96} \mathrm{~N}_{2} \mathrm{O}_{35}: \mathrm{C}, 62.49 ; \mathrm{H}, 5.30$. Found: $\mathrm{C}, 62.38 ; \mathrm{H}, 5.42$.

4-Methoxyphenyl O-(3,4,6-tri-O-acetyl-2-deoxy-2-phthalimido- $\beta$-D-giucopyranosyl $)-(1 \rightarrow 4)-\mathrm{O}-(6-\mathrm{O}-\mathrm{le}$ vulinoyl-2,3-di-O-p-toluoyl- $\beta$-D-glucopyranosyl)-(1 $\rightarrow 3)$-O-(4,6-di-O-acetyl-2-deoxy-2-phthalimido- $\beta$-D-gluco-

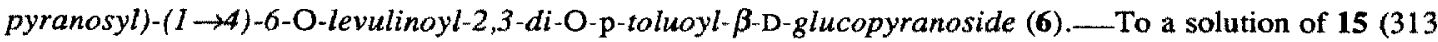
$\mathrm{mg}, 0.17 \mathrm{mmol})$ in pyridine $(6.6 \mathrm{~mL})$ and acetic anhydride $(6.6 \mathrm{~mL})$ was added 4-dimethylaminopyridine $(5$ $\mathrm{mg})$. After stirring overnight, $\mathrm{TLC}\left(4: 1 \mathrm{CH}_{2} \mathrm{Cl}_{2}\right.$-acetone) showed the $O$-acetylation to be complete $\left(6 ; R_{\mathrm{F}} 0.75\right)$, and the mixture was diluted with EtOAc $(100 \mathrm{~mL})$, and washed with aq saturated $\mathrm{NaHCO}_{3}(3 \times 25 \mathrm{~mL})$ and water ( $3 \times 25 \mathrm{~mL}$ ). The organic layer was dried $\left(\mathrm{MgSO}_{4}\right)$, filtered, concentrated, and co-concentrated with toluene, $\mathrm{EtOH}$, and $\mathrm{CH}_{2} \mathrm{Cl}_{2}$ (each $3 \times 25 \mathrm{~mL}$ ). Column chromatography (4:1 $\mathrm{CH}_{2} \mathrm{Cl}_{2}$-acetone) of the residue yield- 
ed 6, isolated as a syrup ( $326 \mathrm{mg}, 99 \%),[\alpha]_{D}+38$ (c 1). NMR data: ${ }^{1} \mathrm{H}, \delta 1.763,1.861,1.871,1.890$, and 1.940 (5 s, each $3 \mathrm{H}, 5 \mathrm{Ac}$ ), 2.159 and 2.226 (2 s, each $3 \mathrm{H}, 2 \mathrm{COCH}_{2} \mathrm{CH}_{2} \mathrm{COCH}_{3}$ ), 2.294, 2.333, 2.363, and $2.373\left(4 \mathrm{~s}\right.$, each $\left.3 \mathrm{H}, 4 \mathrm{COC}_{6} \mathrm{H}_{4} \mathrm{CH}_{3}\right), 3.683\left(\mathrm{~s}, 3 \mathrm{H}, \mathrm{C}_{6} \mathrm{H}_{4} \mathrm{OCH}_{3}\right), 4.282$ and $4.936(2 \mathrm{~d}$, each $1 \mathrm{H}$, $J_{1,2 / 1^{\prime \prime 2}, 2^{\prime \prime}} 7.6$ and $\left.7.4 \mathrm{~Hz}, \mathrm{H}-1,1^{\prime \prime}\right), 5.037$ and 5.282 ( $2 \mathrm{~d}$, each $1 \mathrm{H}, J_{1 ', 2}{ }^{\prime \prime} \mathbf{1}^{\prime \prime}, 2^{\prime \prime \prime} 8.3$ and $\left.8.1 \mathrm{~Hz}, \mathrm{H}-1^{\prime}, 1^{\prime \prime \prime}\right)$, 6.670 and $6.769\left(2 \mathrm{~d}\right.$, each $\left.2 \mathrm{H}, \mathrm{C}_{6} \mathrm{H}_{4} \mathrm{OCH}_{3}\right), 7.001,7.047,7.123,7.132,7.355,7.685,7.751$, and $7.807(8$ d, each $\left.2 \mathrm{H}, 4 \mathrm{COC}_{6} \mathrm{H}_{4} \mathrm{CH}_{3}\right) ;{ }^{13} \mathrm{C}, \delta 19.6,20.1,20.4,20.5$, and $20.6\left(5 \mathrm{COCH}_{3}\right), 21.5\left(\mathrm{COC}_{6} \mathrm{H}_{4} \mathrm{CH}_{3}\right)$, $27.4,27.5,29.1,29.7$, and 37.7 (2 C) $\left(2 \mathrm{COCH}_{2} \mathrm{CH}_{2} \mathrm{COCH}_{3}\right), 54.5$, 55.2, and $55.4\left(\mathrm{C}-2^{\prime}, 2^{2 \prime}, \mathrm{C}_{6} \mathrm{H}_{4} \mathrm{O}-\right.$ $\left.\mathrm{CH}_{3}\right), 61.4$ and $62.4\left(\mathrm{C}-6,6^{\prime}, 6^{\prime \prime}, 6^{\prime \prime \prime}\right), 97.4$ and 97.5 (C-1', $\left.1^{\prime \prime \prime}\right), 99.9$ and $100.6\left(\mathrm{C}-1,1^{\prime \prime}\right), 114.2(2 \mathrm{C})$, $118.6(2 \mathrm{C}), 150.7$, and $155.4\left(\mathrm{C}_{6} \mathrm{H}_{4} \mathrm{OCH}_{3}\right), 164.7,164.9(2 \mathrm{C})$, and $165.0\left(4 \mathrm{COC}_{6} \mathrm{H}_{4} \mathrm{CH}_{3}\right), 168.4,169.1$, $169.9,170.2$, and $170.4\left(5 \mathrm{COCH}_{3}\right), 171.5$ and $171.7\left(2 \mathrm{COCH}_{2} \mathrm{CH}_{2} \mathrm{COCH}_{3}\right)$.

Anal. Calc. for $\mathrm{C}_{99} \mathrm{H}_{100} \mathrm{~N}_{2} \mathrm{O}_{37}: \mathrm{C}, 62.26 ; \mathrm{H}, 5.28$. Found: $\mathrm{C}, 62.15 ; \mathrm{H}, 5.29$.

4-Methoxyphenyl O-(3,4,6-tri-O-acetyl-2-deoxy-2-phthalimido- $\beta$-D-glucopyranosyl)-(1-4)-O-(2,3-di-O-

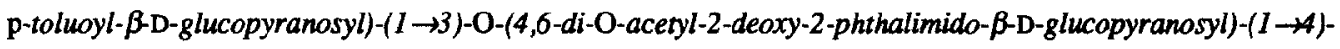
2,3-di-O-p-toluoyl- $\beta$-D-glucopyranoside (16). - To a solution of $6(337 \mathrm{mg}, 0.18 \mathrm{mmol})$ in EtOH $(25.2 \mathrm{~mL})$ and toluene $\left(12.5 \mathrm{~mL}\right.$ ) was added $\mathrm{NH}_{2} \mathrm{NH}_{2}$.HOAc (162 mg). After stirring for $30 \mathrm{~min}$, TLC (4:1 $\mathrm{CH}_{2} \mathrm{Cl}_{2}$-acetone) showed the reaction to be complete $\left(16 ; R_{\mathrm{F}} 0.63\right)$, and the mixture was concentrated. Column chromatography (9:1 $\mathrm{CH}_{2} \mathrm{Cl}_{2}$-acetone) of the residue yielded 16 , isolated as a syrup (262 $\mathrm{mg}, 87 \%$ ), $[\alpha]_{\mathrm{D}}+59$ (c 1 ). NMR data: ${ }^{1} \mathrm{H}, \delta 1.779,1.836,1.882,1.913$, and $1.946(5 \mathrm{~s}$, each $3 \mathrm{H}, 5 \mathrm{Ac}), 2.337$ and 2.362 (2 s, each 6 $\left.\mathrm{H}, 4 \mathrm{COC}_{6} \mathrm{H}_{4} \mathrm{CH}_{3}\right), 3.690$ (s, $3 \mathrm{H}, \mathrm{C}_{6} \mathrm{H}_{4} \mathrm{OCH}_{3}$ ), 4.504 and 4.990 (2 d, each $1 \mathrm{H}, J_{1,2 / 1 ", 2 "} 7.2$ and $7.7 \mathrm{~Hz}$,

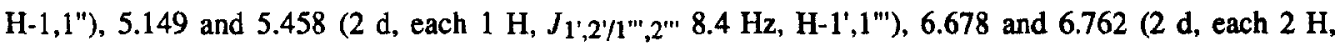
$\left.\mathrm{C}_{6} \mathrm{H}_{4} \mathrm{OCH}_{3}\right), 7.033,7.118,7.124,7.142,7.444,7.721,7.755$, and $7.816\left(8 \mathrm{~d}\right.$, each $\left.2 \mathrm{H}, 4 \mathrm{COC}_{6} \mathrm{H}_{4} \mathrm{CH}_{3}\right)$; ${ }^{13} \mathrm{C}, \delta 20.0-20.2\left(\mathrm{COCH}_{3}\right), 20.4$ and $21.4(3 \mathrm{C})\left(4 \mathrm{COC}_{6} \mathrm{H}_{4} \mathrm{CH}_{3}\right), 54.5,55.2$, and $55.3\left(\mathrm{C}-2,22^{\prime \prime \prime}, \mathrm{C}_{6} \mathrm{H}_{4} \mathrm{O}-\right.$ $\left.\mathrm{CH}_{3}\right), 60.2,60.4,61.0$, and $61.4\left(\mathrm{C}-6,6^{\prime}, 6^{\prime \prime}, 6^{\prime \prime \prime}\right), 97.7\left(\mathrm{C}-1^{\prime}, 1^{\prime \prime \prime}\right), 99.3$ and 100.1 (C-1,1"), 114.3 (2 C), $118.3(2 \mathrm{C}), 150.7$, and $155.4\left(\mathrm{C}_{6} \mathrm{H}_{4} \mathrm{OCH}_{3}\right), 164.6$ and $164.9\left(\mathrm{COC}_{6} \mathrm{H}_{4} \mathrm{CH}_{3}\right), 169.0,169.2(2 \mathrm{C}), 169.8$, and $170.2\left(5 \mathrm{COCH}_{3}\right)$.

Anal. Calc. for $\mathrm{C}_{89} \mathrm{H}_{88} \mathrm{~N}_{2} \mathrm{O}_{33}$ : C, 62.38; H, 5.18. Found: $\mathrm{C}, 62.46 ; \mathrm{H}, 5.28$.

4-Methoxyphenyl O-(3,4,6-tri-O-acetyl-2-deoxy-2-phthalimido- $\beta$-D-glucopyranosyl)-(1-4)-O-(2,3-di-Op-tolwoyl- $\beta$-D-glucopyranosyluronic acid)-( $1 \rightarrow 3)$-O-(4,6-di-O-acetyl-2-deoxy-2-phthalimido- $\beta$-D-glucopyrano-

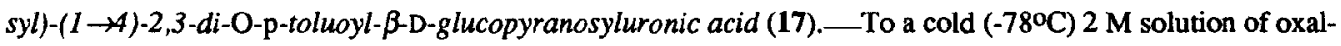
yl chloride in $\mathrm{CH}_{2} \mathrm{Cl}_{2}(645 \mu \mathrm{L})$ was added $\mathrm{Me}_{2} \mathrm{SO}(195 \mu \mathrm{L})$, and the mixture was stirred for $10 \mathrm{~min}$. Then a solution of $16(113 \mathrm{mg}, 65.9 \mu \mathrm{mol})$ in $\mathrm{CH}_{2} \mathrm{Cl}_{2}(1.1 \mathrm{~mL})$ was added, and the mixture was stirred for $5 \mathrm{~h}$, whereby within $15 \mathrm{~min}$ a precipitate was observed. Diisopropylethylamine $(0.96 \mathrm{~mL})$ was added, and after $10 \mathrm{~min}$ the mixture was diluted with EtOAc ( $50 \mathrm{~mL})$, and washed with $\mathrm{M} \mathrm{HCl}(2 \times 15 \mathrm{~mL})$ and aq saturated $\mathrm{NaCl}(2 \times 15$ $\mathrm{mL}$ ). The organic layer was dried $\left(\mathrm{MgSO}_{4}\right)$, filtered, and concentrated. To a solution of the residue in $t$-BuOH $(5.4 \mathrm{~mL}), 2$-methylbutene $(2.0 \mathrm{~mL})$, and water $(3.4 \mathrm{~mL})$ were added $\mathrm{NaH}_{2} \mathrm{PO}_{4}(336 \mathrm{mg})$ and $\mathrm{NaClO}_{2}(336$ $\mathrm{mg}$ ). The mixture was stirred overnight, when $\mathrm{TLC}\left(5: 5: 1 \mathrm{CH}_{2} \mathrm{Cl}_{2}\right.$-EtOAc-HOAc) showed a complete conversion of 16 into $17\left(R_{\mathrm{F}} 0.83\right)$. Then, the mixture was concentrated, and a solution of the residue in water was washed with hexane, acidified with $\mathrm{M} \mathrm{HCl}$, and extracted with EtOAc $(3 \times 30 \mathrm{~mL})$. The organic layer was dried $\left(\mathrm{MgSO}_{4}\right)$, filtered, and concentrated. Column chromatography $\left(3: 2 \mathrm{CH}_{2} \mathrm{Cl}_{2}\right.$-EtOAc followed by $5: 5: 1 \mathrm{CH}_{2} \mathrm{Cl}_{2}-$ 
EtOAc-HOAc) of the residue yielded 17 , isolated as a syrup $(88 \mathrm{mg}, 76 \%)$, $[\alpha]_{D}+6$ (c 1$)$. NMR data: ${ }^{1} \mathrm{H}, \delta$ $1.757,1.824,1.842$, and $1.881(4 \mathrm{~s}, 3,3,3,6 \mathrm{H}, 5 \mathrm{Ac}), 2.298,2.333,2.344$, and 2.382 (4 s, each $3 \mathrm{H}, 4$ $\left.\mathrm{COC}_{6} \mathrm{H}_{4} \mathrm{CH}_{3}\right), 3.689\left(\mathrm{~s}, 3 \mathrm{H}, \mathrm{C}_{6} \mathrm{H}_{4} \mathrm{OCH}_{3}\right), 3.783$ and 3.859 (2 d, each $1 \mathrm{H}, J_{5,4 / 5 ", 4 "} 9.5$ and $9.0 \mathrm{~Hz}, \mathrm{C}-$ $\left.5,5^{\prime \prime}\right), 4.438$ and 5.057 ( $2 \mathrm{~d}$, each $1 \mathrm{H}, J_{1,2 / 1^{\prime \prime}, 2^{\prime \prime}} 7.5$ and $\left.7.7 \mathrm{~Hz}, \mathrm{H}-1,1^{\prime \prime}\right), 5.370$ and 5.567 ( $2 \mathrm{~d}$, each $1 \mathrm{H}$,

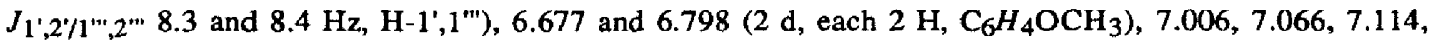
$7.147,7.369,7.706,7.782$, and $7.832\left(8 \mathrm{~d}\right.$, each $\left.2 \mathrm{H}, 4 \mathrm{COC}_{6} \mathrm{H}_{4} \mathrm{CH}_{3}\right) ;{ }^{13} \mathrm{C}, \delta 20.2,20.3(2 \mathrm{C})$, and $20.5(2$ C) $\left(5 \mathrm{COCH}_{3}\right), 21.5\left(\mathrm{COC}_{6} \mathrm{H}_{4} \mathrm{CH}_{3}\right), 54.4,55.2$, and $55.5\left(\mathrm{C}-2^{\prime}, 2^{\prime \prime \prime}, \mathrm{C}_{6} \mathrm{H}_{4} \mathrm{OCH}_{3}\right), 61.6$ and $62.0\left(\mathrm{C}-6,6^{\prime}\right.$, $\left.6^{\prime \prime}, 6^{\prime \prime \prime}\right), 97.3$ and 97.7 (C-1',1"'), 100.4 and 100.7 (C-1,1"), 114.4 (2 C), 118.5 (2 C), 150.6, and 155.5 $\left(C_{6} \mathrm{H}_{4} \mathrm{OCH}_{3}\right), 163.4(\mathrm{COOH}), 164.8,164.9,165.0$, and $165.1\left(4 \mathrm{COC}_{6} \mathrm{H}_{4} \mathrm{CH}_{3}\right), 169.7,170.0,170.1$, 170.8, and $171.1\left(5 \mathrm{COCH}_{3}\right)$. A small amount of 17 was esterified with diazomethane in ether, and analysed with ${ }^{1} \mathrm{H}$ NMR: $\delta 1.767,1.884,1.894$, and $1.908(4 \mathrm{~s}, 6,3,3,3 \mathrm{H}, 5 \mathrm{Ac}), 2.308,2.340$, and $2.38 .5(3 \mathrm{~s}, 3,6,3$ $\left.\mathrm{H}, 4 \mathrm{COC}_{6} \mathrm{H}_{4} \mathrm{CH}_{3}\right), 3.386$ and $3.577\left(2 \mathrm{~s}\right.$, each $\left.3 \mathrm{H}, 2 \mathrm{COOCH}_{3}\right), 3.686\left(\mathrm{~s}, 3 \mathrm{H}, \mathrm{C}_{6} \mathrm{H}_{4} \mathrm{OCH}_{3}\right), 3.722$ and 3.794 ( $2 \mathrm{~d}$, each $1 \mathrm{H}, J_{5,4 / 5 ", 4 "} 9.7$ and $\left.8.9 \mathrm{~Hz}, \mathrm{C}-5,5^{\prime \prime}\right), 4.355$ and 5.002 ( $2 \mathrm{~d}$, each $1 \mathrm{H}, J_{1,2 / 1^{\prime \prime}, 2 "} 7.6$ and

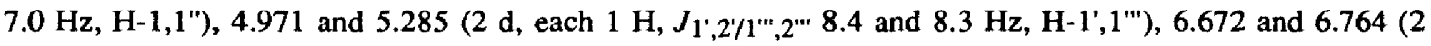
d, each $2 \mathrm{H}, \mathrm{C}_{6} \mathrm{H}_{4} \mathrm{OCH}_{3}$ ), 6.999, 7.074, 7.122, 7.131, 7.353, 7.693, 7.761, and 7.828 (8 d, each $2 \mathrm{H}, 4$ $\mathrm{COC}_{6} \mathrm{H}_{4} \mathrm{CH}_{3}$ ).

4-Methoxyphenyl O-(2-acetamido-2-deoxy- $\beta$-D-glucopyranosyl)-( $(1 \rightarrow 4)-\mathrm{O}-(\beta$-D-glucopyranosyluronic acid $)$ - $(I \rightarrow 3)$-O-(2-acetamido-2-deoxy- $\beta$-D-glucopyranosyl)-( $(-4)$ - $\beta$-D-glucopyranosyluronic acid (5). - A solution of $17(50 \mathrm{mg}, 29 \mu \mathrm{mol})$ in ethanolic $33 \%$ methylamine ( $40 \mathrm{~mL}$ ) was stirred for 3 days, and after concentration the residue was taken up in $\mathrm{MeOH}(6.4 \mathrm{~mL})$ and acetic anhydride $(179.6 \mu \mathrm{L})$. The solution was stirred for $2 \mathrm{~h}$ at $0^{\circ} \mathrm{C}$, when TLC (4:2:2:1 $n$-BuOH-EtOH-H $\left.\mathrm{H}_{2} \mathrm{O}-\mathrm{HOAC}\right)$ showed the formation of $5\left(R_{\mathrm{F}} 0.55\right)$. The mixture was concentrated, and 1:1 MeOH-toluene $(3 \times 30 \mathrm{~mL})$ was evaporated from the residue. Then the residue was dissolved in $\mathrm{MeOH}$, and $\mathrm{NaOMe}$ was added until $\mathrm{pH}$ 10. After stirring overnight, 5 drops of water were added and the stirring was continued for $2 \mathrm{~h}$ at room temperature. Then Dowex $50\left(\mathrm{H}^{+}\right)$was added to neutralize, and the mixture was filtered and concentrated. Gelfiltration of the residue on Sephadex G-10 (water) followed by Bio-Gel P-2 (water), yielded 5, isolated after lyophilisation as a white, amorphous powder (16 mg, $61 \%$ ), $[\alpha]_{\mathrm{D}}-45$ (c 1, water). ${ }^{1} \mathrm{H}-\mathrm{NMR}$ data $\left(\mathrm{D}_{2} \mathrm{O}\right): \delta 2.026$ and 2.046 (2 s, each $\left.3 \mathrm{H}, \mathrm{NHCOCH}_{3}\right), 3.810$ (s, $\left.3 \mathrm{H}, \mathrm{C}_{6} \mathrm{H}_{4} \mathrm{OCH}_{3}\right), 4.491,4.541$, and 4.591 (3 d, each $1 \mathrm{H}, J_{1}^{\prime}, 2^{\prime} / 1^{\prime \prime}, 2^{\prime \prime} / 1^{\prime \prime}, 2^{\prime \prime \prime} 7.8,8.2$, and $8.4 \mathrm{~Hz}, \mathrm{H}-1^{\prime}, 1^{\prime \prime}$, $\left.1^{\prime \prime \prime}\right), 5.015$ (d, $1 \mathrm{H}, J_{1,2} 7.3 \mathrm{~Hz}, \mathrm{H}-1$ ), 6.977 and 7.102 (2 d, each $2 \mathrm{H}, \mathrm{C}_{6} \mathrm{H}_{4} \mathrm{OCH}_{3}$ ); FAB-MS $m / z 883$ $[\mathrm{M}+\mathrm{H}]^{+}$.

\section{ACKNOWLEDGMENTS}

The research of Dr. T.M. Slaghek has been made possible by a fellowship of the Royal Netherlands Academy of Art and Sciences. The authors would like to thank Mrs. A.C.H.T.M. van der Kerk-van Hoof for recording the FAB-MS spectra. 


\section{REFERENCES}

1. Laurent, T. C.; Fraser, J. R. E. FASEB J. 1992, 6, 2397-2404.

2. Meyer, K. Fed. Proc., Fed. Am. Chem. Soc. Exp. Biol. 1958, 17, 1075-1077.

3. Prehm, P. Biochem. J. 1984, 220, 597-600.

4. Aruffo, A.; Stamenkovic, I.; Melnick, M.; Underhill, C. B.; Seed, B. Cell 1990, 61, 1303-1313.

5. Toole, B. P. In Cell Biology of Extracellular Matrix, Hay, E. D. Ed.; Plenum Press, New York, USA, 1991, pp. 305-341.

6. Ellis, I.; Grey, A. M.; Schor, A. M.; Schor, S. L. J. Cell Sci. 1992, 102, 447-456.

7. West, D. C.; Kumar, S. In The Biology of Hyaluronan, Evered, D.; Whelan, J. Eds.; Ciba Foundation Symposium 143, Wiley, Chichester, UK, 1989, pp. 187-207.

8. Balazs, E. A.; Denlinger, J. L. In The Biology of Hyaluronan, Evered, D.; Whelan, J. Eds.; Ciba Foundation Symposium 143, Wiley, Chichester, UK, 1989, pp. 265-280.

9. King, S. R.; Hickerson, W. L.; Proctor, K. G.; Newsome, A. M. Surgery 1991, 109, 76-84.

10. Engström-Laurent, A. In The Biology of Hyaluronan, Evered, D.; Whelan, J. Eds.; Ciba Foundation Symposium 143, Wiley, Chichester, UK, 1989, pp. 233-247.

11. West, D. C.; Hampson, I. N.; Arnold, F.; Kumar, S. Science 1985, 228, 1324-1326.

12. Slaghek, T. M.; Nakahara, Y.; Ogawa, T.; Kamerling, J. P.; Vliegenthart, J. F. G. Carbohydr. Res. 1994, 255, 61-85.

13. Slaghek, T. M.; Hyppönen, T.K.; Ogawa, T.; Kamerling, J. P.; Vliegenthart, J. F. G. Tetrahedron Lett. 1993, 34, 7939-7942.

14. Carter, M. B.; Petillo, P. A.; Anderson, L.; Lemer, L. E. Carbohydr. Res. 1994, 258, 299-306.

15. Schmidt, R. R.; Michel, J.; Roos, M. Liebigs Ann. Chem. 1984, 1343-1357.

16. Van Boom, J. H.; Burgers, P. M. J. Tetrahedron Lett. 1976, 4875-4878.

17. Jeker, N.; Tamm, C. Helv. Chim. Acta 1988, 71, 1895-1903.

18. Omura, K.; Swern, D. Tetrahedron 1978, 34, 1651-1660.

19. Lindgren, B. O.; Nilsson, T. Acta Chem. Scand. 1973, 27, 888-890.

20. Motawia, M. S.; Wengel, J.; Abdel-Megid, A. E.-S.; Pedersen, E. B. Synthesis 1989, 384-387.

21. Fukuyama, T.; Laird, A. A.; Hotchkiss, L. M. Tetrahedron Lett. 1985, 26, 6291-6292.

22. Kunz, H.; Waldmann, H. Angew. Chem. 1984, 96, 49-50.

23. Hayakawa, Y.; Kato, H.; Uchiyama, M.; Kajino, H.; Noyori, R. J. Org. Chem. 1986, 51, 24002402.

(Received 16 September 1994) 